\title{
Work related musculoskeletal disorders in physical therapists: a systematic review
}

\author{
Muhammad Hamad Haleem ${ }^{1}$, Ikram Ali ${ }^{2}$, Savera Khan ${ }^{3}$, Abdullah Jehangir ${ }^{4}$, Irfan Ullah ${ }^{5}$
}

\author{
Submitted: \\ December 4, 2020 \\ Accepted: \\ December 20, 2020 \\ Author Information
${ }^{1-5}$ Khyber Medical University Institute
of Physical Medicine and Rehabilitation
}

\section{Corresponding Author}

Ikram Ali

Khyber Medical University Institute of

Physical Medicine and Rehabilitation

Email: drikramali@gmail.com

\begin{abstract}
Introduction: Physical therapists are required to perform tasks that predispose them to developing work related musculoskeletal disorders. The physical therapists personal and professional life can be affected by work related musculoskeletal disorders. High level evidence is lacking regarding work related musculoskeletal disorders. The purpose of this study was to combine information on prevalence, risk factors and the consequences of work-related musculoskeletal disorders in physical therapists.

Material \& Methods: A systematic review was conducted according to PRISMA guidelines. Three members independently searched the databases PubMed and other online sources including google scholar for relevant data from July 2014 to September 2020. Cross-sectional studies published in English language which reported work related musculoskeletal disorders in physical therapists were included. Studies involving physical therapy students and internees, having insufficient information about past or current work-related musculoskeletal disorders, sample size of physical therapists less than 50 and not published in peer reviewed journals were excluded.

Results: Twenty one articles were included in current systematic review. The 1-year prevalence of workrelated musculoskeletal disorders among physical therapists ranged from $38.5 \%$ to $97.6 \%$. The low back was the commonest affected body part. Treating large number of patients and manual therapy were the leading risk factors for developing work related musculoskeletal disorders. The most common consequences were modifying treatment techniques and reducing work hours.

Conclusion: Prevalence of work related musculoskeletal disorders are high among physical therapists. The nature of physical therapy job presents significant risk factors which can lead to work related musculoskeletal disorders.

Key Words: Manual, Musculoskeletal, Occupation, Pain, Physical Therapist.
\end{abstract}

The authors declared no conflict of interest and agreed to be accountable for all aspects of the work in ensuring that questions related to the accuracy or integrity of any part of the work are appropriately investigated and resolved.

All authors contributed substantially to the planning of research, questionnaire design, data collection, data analysis and write-up of the article as part of a student research team at Khyber Medical University Institute of Physical Medicine and Rehabilitation The research work was supervised by Dr. Ikram Ali (PT) Assistant Professor Khyber Medical University Institute of Physical Medicine and Rehabilitation.

This article may be cited as:Haleem MH, Ali I, Khan S, Jehangir A, Ullah I. Work related musculoskeletal disorders in physical therapists: a systematic review. Reh J Health Sci. 2020;2(2). 28-35

\section{INTRODUCTION}

Health care workers are prone to develop work related musculoskeletal disorders (WMSDs). ${ }^{1-4}$ Working posture and prolong hours work are commonly reported risk factors for WMSDs. ${ }^{5}$ WMSDs can be defined as problems of the musculoskeletal system which are caused by work and results in discomfort, difficulty and pain performing work. The health workers whose jobs require labor intensive tasks are at risk of developing WMSDs. Physical therapists (PTs) are particularly prone to developing WMSDs because of the nature of their work (prolonged standing, awkward postures and other activities) and the application of physical therapy treatment in the form of various hands on techniques. At entry level degree education, physical therapists are trained in injury prevention and correct use of body mechanics to avoid abnormal forces on the body. This may lead to the belief that WMSDs occur less frequently in PTs than other health professionals. ${ }^{6}$ Contrary to this, the prevalence of WMSDs in PTs is comparable to other professions involving lifting or other physically demanding tasks. ${ }^{7,8}$ The most common risk factors associated with WMSDs in PTs are large physical loads. ${ }^{9-11}$
On organizational level, WMSDs can create economic burden and results in economic loss whereas on individual level WMSDs can result in loss of productivity, disability and an increased focus on therapist's own health care, ultimately leading to poor outcomes of treatment sessions for patients. ${ }^{5,12,13}$ Because high level evidence is lacking regarding WMSDs in PTs, therefore, this review was designed to integrate the information available on WMSDs in PTs, risk factors associated with it and the consequences of WMSDs on physical therapists and their clinical practice.

\section{MATERIALS \& METHODS}

A systematic review was conducted according to PRISMA guidelines. Three members independently searched the database PubMed and other online sources including google scholar for relevant data from July 2014 to September 2020. The search term "work related injury" OR "work related disorders" OR “job related disorders" OR "occupational injury" OR "occupational disease” OR "occupational disorder" AND "musculoskeletal disease" OR "musculoskeletal disorder" OR "musculoskeletal injury" OR "musculoskeletal pain" OR "musculoskeletal discomfort" OR "MSI" OR "MSD” AND "physical therapist" OR "manual 
therapist" OR "hand therapist" were used. Cross-sectional studies published in English language which reported work related musculoskeletal disorders in physical therapists were included. Studies involving physical therapy students and internees, having insufficient information about past or current work-related musculoskeletal disorders, sample size of physical therapists less than 50 and not published in peer reviewed journals were excluded.

The retrieved articles were imported to the reference manager software 'End Note X7'. Two members independently screened the titles and abstracts and with mutual agreement included all the relevant studies for further screening on the basis of eligibility criteria. Where disagreements persisted, the third member was asked for his opinion and subsequently the articles were included or excluded. The variables which were extracted from the studies included age, work setting, work experience, body parts affected, most common body part affected, 1 year prevalence of WMSDs, risk factors for WMSDs and consequences of WMSDs.The included studies were assessed for quality using the NIH assessment tool for cross sectional studies.

\section{RESULTS}

The search on google scholar yielded 17200 results while PubMed resulted in 212 articles. After screening on the basis of title, 55 articles were identified for further screening. 43 articles remained after duplicate removal. The screening on the basis of abstract resulted in a total of 26 . These 26 articles were subjected to full text reading. As a result, 5 articles were excluded on the basis of involving students and internees $(\mathrm{n}=2)$, a mixed methods study $(\mathrm{n}=1)$ and not published in a peer reviewed journal $(\mathrm{n}=2)$. (Figure 1) Majority of the included studies had low to moderate quality. (Table 1)

The one-year prevalence of WMSDs among PTs ranged from $38.5 \%$ to $97.6 \%$ ). The lower back was found to be the most commonly affected body part with a prevalence ranging from $32 \%$ to $90 \%$. The second most common affected body part was the neck with a prevalence that ranged from $26.6 \%$ to $72 \%$. The third most common was shoulder with prevalence that ranged from $12 \%$ to $68.3 \%$ (Table 2). The most commonly associated activities with WMSDs were treating large number of patients and manual therapy (Table 3). The most common reported consequences were altering/modifying treatment technique and decrease in work hours (Table 4).

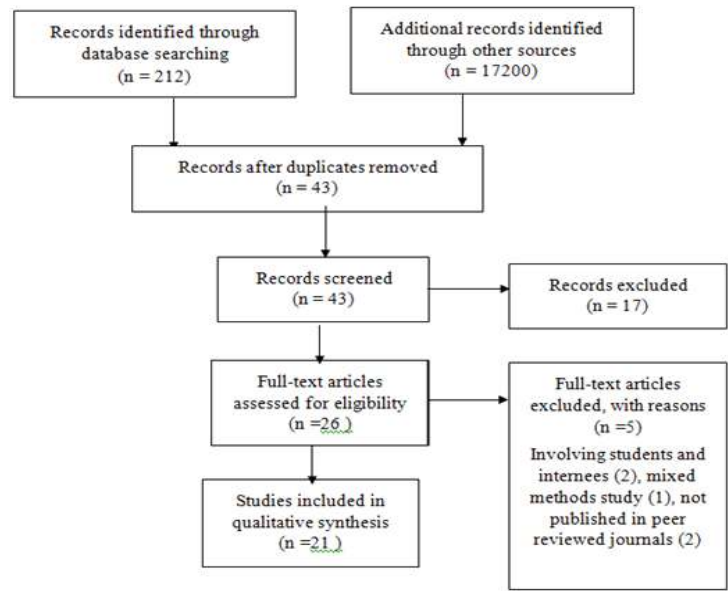

Figure 1: Flow Diagram

Table1: NIH Quality Assessment

\begin{tabular}{|c|c|c|c|c|c|c|c|c|c|c|c|c|c|c|c|}
\hline Study name & 1 & 2 & 3 & 4 & 5 & 6 & 7 & 8 & 9 & 10 & 11 & 12 & 13 & 14 & $\begin{array}{c}\text { Total } \\
14 \\
\end{array}$ \\
\hline Abaraogu et al. & Yes & Yes & Yes & Yes & No & NA & NA & NA & Yes & NA & Yes & NA & NA & NA & 6 \\
\hline Alghadir et al. & Yes & Yes & Yes & Yes & No & NA & NA & NA & Yes & NA & Yes & NA & NA & NA & 6 \\
\hline Alnaser and Aljadi. & Yes & Yes & Yes & Yes & No & NA & NA & NA & Yes & NA & Yes & NA & NA & NA & 6 \\
\hline $\begin{array}{l}\text { Anyfantis and } \\
\text { Biska. }\end{array}$ & Yes & Yes & Yes & N/R & No & NA & NA & NA & Yes & NA & Yes & NA & NA & NA & 5 \\
\hline Bae and Min. & Yes & Yes & Yes & N/R & No & NA & NA & NA & Yes & NA & Yes & NA & NA & NA & 5 \\
\hline Bae Young Hyeon. & Yes & Yes & Yes & Yes & No & NA & NA & NA & Yes & NA & Yes & NA & NA & NA & 6 \\
\hline Cornwell et al. & Yes & Yes & Yes & Yes & No & NA & NA & NA & Yes & NA & Yes & NA & NA & NA & 6 \\
\hline Ezzatvar et al. & Yes & Yes & Yes & Yes & Yes & NA & NA & NA & Yes & NA & Yes & NA & NA & NA & 7 \\
\hline Gharote et al. & Yes & Yes & Yes & Yes & No & NA & NA & NA & Yes & NA & Yes & NA & NA & NA & 6 \\
\hline Greiner et al. & Yes & Yes & Yes & $\mathrm{CD}$ & Yes & NA & NA & NA & Yes & NA & Yes & NA & NA & NA & 6 \\
\hline Islam et al. & Yes & Yes & Yes & N/R & No & NA & NA & NA & Yes & NA & Yes & NA & NA & NA & 5 \\
\hline Mahajan et al. & Yes & Yes & Yes & Yes & No & NA & NA & NA & Yes & NA & Yes & NA & NA & NA & 6 \\
\hline Meh et al. & Yes & Yes & Yes & Yes & No & NA & NA & NA & Yes & NA & Yes & NA & NA & NA & 6 \\
\hline Muaidi and Shanb. & Yes & Yes & Yes & Yes & No & NA & NA & NA & Yes & NA & Yes & NA & NA & NA & 6 \\
\hline Mubeen et al. & Yes & Yes & Yes & Yes & No & NA & NA & NA & Yes & NA & Yes & NA & NA & NA & 6 \\
\hline Rahimi et al. & Yes & Yes & Yes & N/R & Yes & NA & NA & NA & Yes & NA & Yes & NA & NA & NA & 6 \\
\hline Raoof et al. & Yes & Yes & Yes & Yes & Yes & NA & NA & NA & Yes & NA & Yes & NA & NA & NA & 7 \\
\hline Rasha AE et al. & Yes & Yes & Yes & $\mathrm{N} / \mathrm{R}$ & No & NA & NA & NA & Yes & NA & Yes & NA & NA & NA & 5 \\
\hline Rossettini et al. & Yes & Yes & No & $\mathrm{CD}$ & No & NA & NA & NA & Yes & NA & Yes & NA & NA & NA & 4 \\
\hline Truszczynska et al. & Yes & Yes & Yes & Yes & No & NA & NA & NA & Yes & NA & Yes & NA & NA & NA & 6 \\
\hline Vieira et al. & Yes & Yes & Yes & Yes & No & NA & NA & NA & Yes & NA & Yes & NA & NA & NA & 6 \\
\hline
\end{tabular}


Table 2: Prevalence of work-related musculoskeletal disorders among Physical therapists

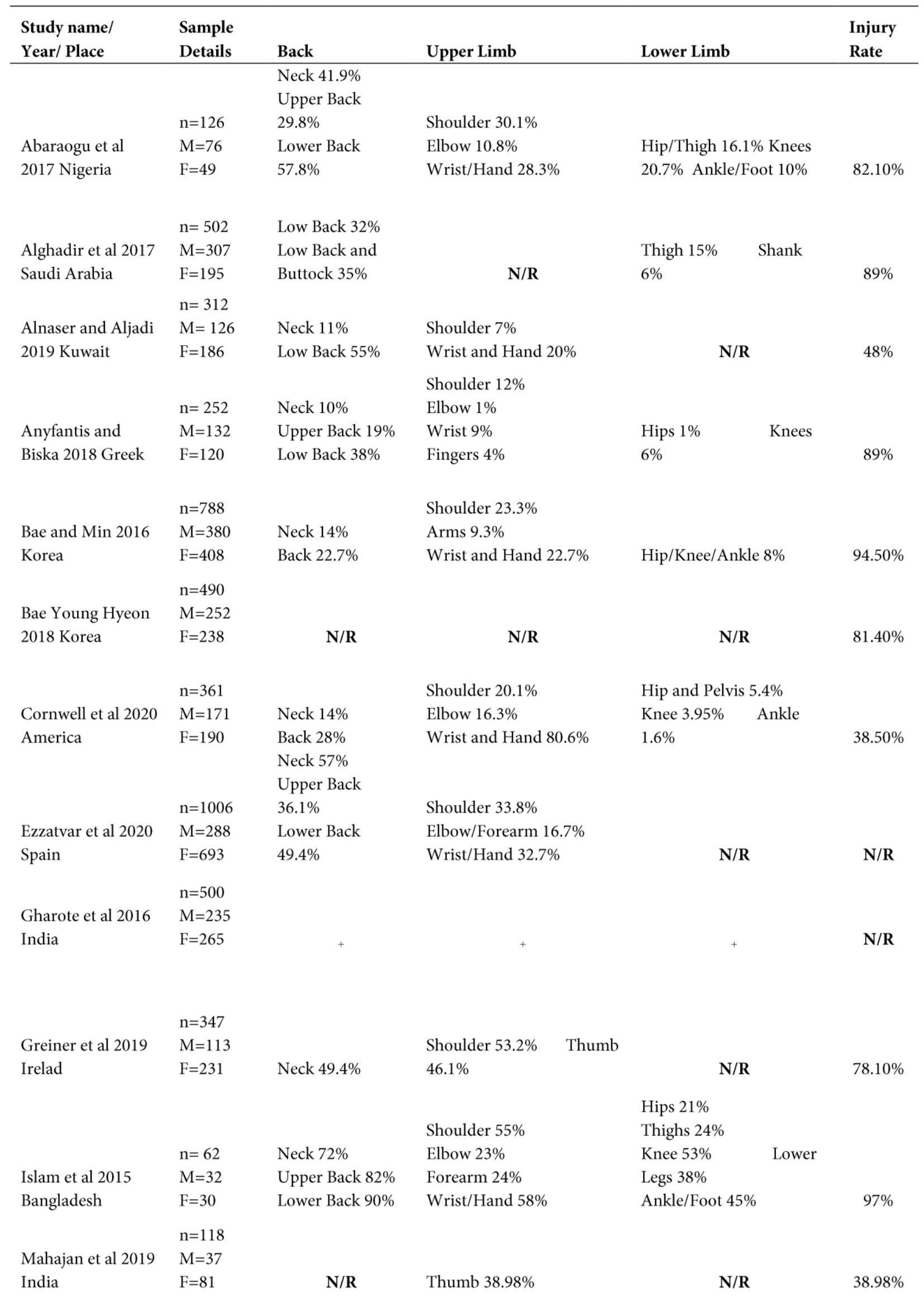




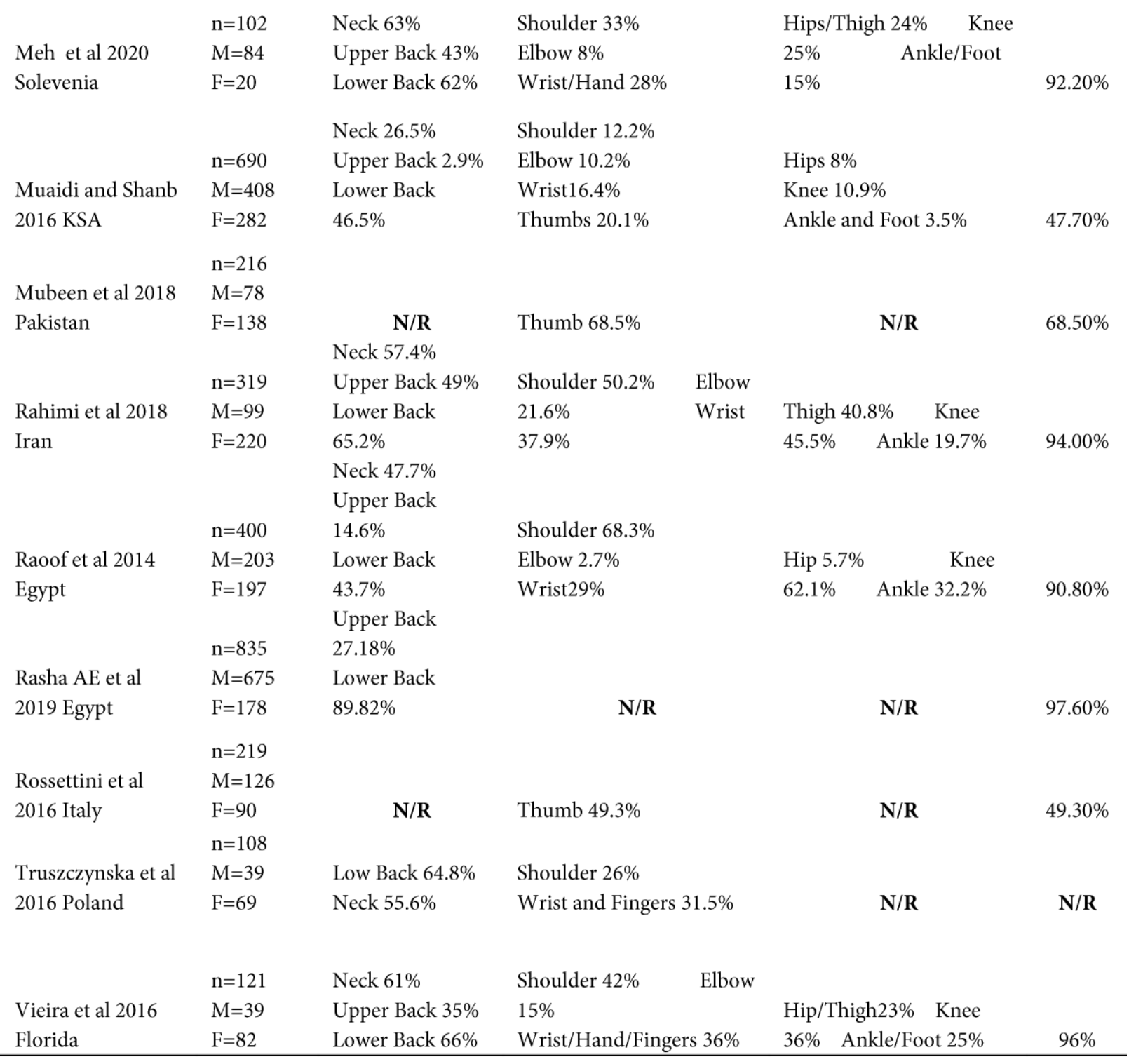




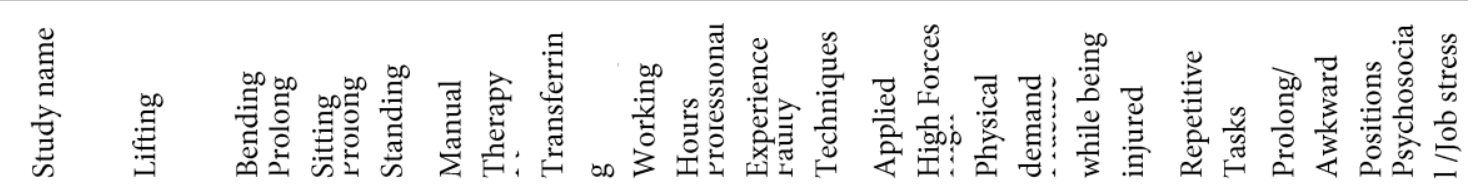

\begin{tabular}{|c|c|c|c|c|c|c|c|c|c|c|c|c|c|c|c|}
\hline $\begin{array}{l}\text { Abaraogu et } \\
\text { al. }\end{array}$ & - & - & - & - & - & - & - & - & - & - & + & - & - & - & + \\
\hline $\begin{array}{l}\text { Alghadir et al. } \\
\text { Alnasir and }\end{array}$ & + & - & $\%$ & - & - & + & $\begin{array}{c}+ \\
56\end{array}$ & - & + & - & + & - & - & - & - \\
\hline Aljadi. & $19 \%$ & - & - & - & $26 \%$ & $25 \%$ & $\%$ & - & + & - & + & $85 \%$ & $5 \%$ & $10 \%$ & - \\
\hline Anyfantis and & & & & & & & & & & & & & & & 60 \\
\hline Biska. & - & + & + & - & - & - & + & + & + & 30 & + & $47 \%$ & $90 \%$ & $70 \%$ & $\%$ \\
\hline $\begin{array}{l}\text { Bae and Min. } \\
\text { Bae Young }\end{array}$ & + & - & - & + & - & + & + & - & - & - & - & - & - & - & - \\
\hline $\begin{array}{l}\text { Hyeon. } \\
\text { Cornwell et }\end{array}$ & - & - & - & - & $\stackrel{+}{+}$ & + & + & + & - & - & + & - & - & - & - \\
\hline al. & - & - & - & - & $0 \%$ & - & - & + & + & - & - & - & - & - & - \\
\hline Ezzatvar et al. & $\begin{array}{c}- \\
41.3\end{array}$ & - & + & - & $\stackrel{+}{+}$ & $\begin{array}{c}- \\
41.3\end{array}$ & + & + & - & - & - & - & - & - & - \\
\hline Gharote et al. & $0 \%$ & + & - & - & $0 \%$ & $0 \%$ & + & - & - & - & - & - & + & + & - \\
\hline Greiner et al. & - & - & - & - & + & - & - & + & - & - & - & - & - & - & + \\
\hline Islam et al. & - & - & - & - & - & - & - & - & - & - & - & - & - & - & - \\
\hline Mahajan et al. & - & - & - & - & + & - & + & - & - & + & - & $\begin{array}{c}- \\
83.3\end{array}$ & + & - & - \\
\hline $\begin{array}{l}\text { Meh et al. } \\
\text { Muaidi and }\end{array}$ & - & $\begin{array}{c}- \\
42.6\end{array}$ & - & - & 29.6 & - & $\stackrel{+}{40}$ & + & - & - & $\begin{array}{c}- \\
34.1\end{array}$ & $0 \%$ & $\begin{array}{c}- \\
40.1\end{array}$ & $\begin{array}{c}- \\
43.5 / 45\end{array}$ & - \\
\hline Shanb. & + & $0 \%$ & - & - & $\begin{array}{c}0 \% \\
68.5\end{array}$ & + & $\begin{array}{c}\% \\
2.30\end{array}$ & - & + & $\begin{array}{c}- \\
52.3\end{array}$ & $0 \%$ & + & $\begin{array}{c}0 \% \\
13.4\end{array}$ & $.9 \%$ & - \\
\hline Mubeen et al. & - & - & - & - & $0 \%$ & - & $\%$ & - & + & $1 \%$ & - & $\begin{array}{c}- \\
73.4\end{array}$ & $0 \%$ & - & - \\
\hline Rahimi et al. & - & + & - & + & - & - & + & - & - & - & - & $0 \%$ & - & - & - \\
\hline $\begin{array}{l}\text { Raoof et al. } \\
\text { Rasha AE et }\end{array}$ & + & + & - & + & + & + & + & - & - & + & - & - & + & + & - \\
\hline al. & - & - & - & - & - & - & + & + & - & - & - & - & - & - & - \\
\hline $\begin{array}{l}\text { Rossettini et } \\
\text { al. }\end{array}$ & - & - & - & - & $\begin{array}{c}68.5 \\
0 \%\end{array}$ & - & - & + & + & - & - & $\begin{array}{c}66.7 \\
0 \%\end{array}$ & - & $64.80 \%$ & $\begin{array}{l}12 \\
\%\end{array}$ \\
\hline $\begin{array}{l}\text { Truszczynska } \\
\text { et al. }\end{array}$ & + & + & - & - & - & + & - & + & - & - & + & - & + & + & + \\
\hline Vieira et al. & + & - & - & - & + & - & + & - & - & - & ${ }_{-}$ & - & + & + & - \\
\hline
\end{tabular}




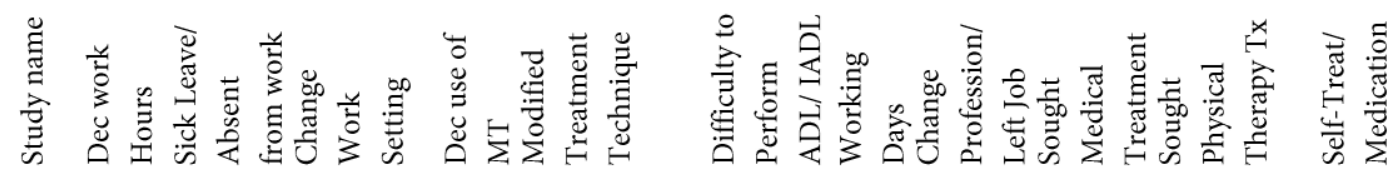

Abaraogu et al.

Alghadir et al.

$11 \%$

$17 \%$

$17 \%$

$10 \%$

Alnaser and

Aljadi.

$13 \%$

Anyfantis and

Biska.

$6 \%$

Bae and Min.

Bae Young

Hyeon.

Cornwell et al. $\quad 50 \%$

42.90

Ezzatvar et al.

Gharote et al.

Greiner et al.

Islam et al.

Mahajan et al. $\quad \%$

\section{$8.70 \quad 32.61$}

$\% \quad \%$

Meh et al.

Muaidi and

Shanb.

Mubeen et al.

Rahimi et al.

Raoof et al.

Rasha AE et al.

$8.80 \%$

$7.70 \%$

$12 \%$

39.81

18.98

$\%$

Rossettini et al.

Truszczynska et

al.

Vieira et al.

$\%$

69.40
$31.2 \% / 33.8$

11.10

33

$\% \quad 48 \%$

$85 \%$

$33 \%$

$6.91 \%$

$\begin{array}{ccc}41.20 & 41.20 & 26.50 \\ \% & \% & \%\end{array}$

$3.50 \%$

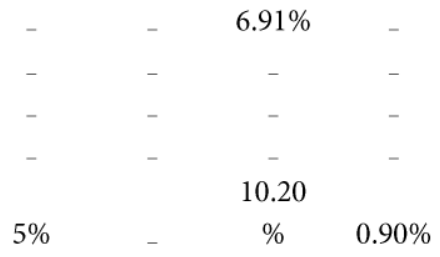




\section{DISCUSSION}

WMSDs are frequently occurring disorders among health care workers. Physical therapists are highly vulnerable to developing WMSDs due to the nature of their job which require high physical demands. Our study evaluated WMSDs in PTs, their prevalence, body parts affected, risk factors associated with WMSDs and their consequences on PTs and their jobs.

Among 21 studies, 5 studies were specifically on thumb, 2 on low back and one study investigated WMSDs in upper limb. No study specifically reported on lower limb WMSDs. The lower back was reported most prevalent in 11 studies followed by the neck and shoulder which were reported most prevalent in 9 studies each. Only one study reported the wrist and hand as most prevalent. The lower limb was reported by several studies but poorly elaborated. The low back WMSDs were well elaborated with several studies reporting the prevalence and risk factors associated with low back WMSDs. The most common risk factors for WMSDs were found to be treating large number of patients and manual therapy. Manual therapy was reported as significant risk factor by Bork et al. who stated that PTs who performed manual therapy were 3.5 times more likely to develop WMSDs. Other frequently associated risk factors were patient transfer, lifting, bending and twisting activities. This reflects the high demands placed on PTs during their work. High physical loads were associated with WMSDs in nurses ${ }^{8}$ but a study found that PTs are more affected by WMSDs because they perform labor intensive tasks even more than nurses. ${ }^{33}$ Ngan et al. stated that poor body mechanics during patient handling is the leading cause for WMSDs in PTs and Nurses. Our study also found that the most common risk factors for lower back WMSDs were patient transfer, lifting, bending and twisting activities which are consistent with previous studies. This can be explained by the fact that all these activities place abnormal stresses on the back thus resulting in back WMSDs.

Literature suggests that manual therapy can cause wrist, hand and thumb pain among physical therapists., Similar results were found in our study. Physical therapists belief that manual therapy is integral part of physical therapy management can lead to reluctance of using alternative techniques which can cause overuse of vulnerable areas. Sustained awkward positions can also contribute to WMSDs as it puts the body in biomechanical disadvantage which can cause significant problems for PTs. In this review, three studies reported on work settings and its association with WMSDs. Only one study did not report any association. However previous studies have shown association between work settings and WMSDs. ,

The association of gender and WMSDs in our studies was inconclusive because several studies reported no association between gender and WMSDs. This finding is in contrast to previous studies who have shown that gender is associated with WMSDs with the female gender more affected than the male. Our study did find that female gender is associated with low back WMSDs which is consistent with a study conducted by Adegoke et al. Neck WMSDs were also found to be associated with female gender which is similar to the findings of previous research. The probable explanation for this may be the inherent differences in the body build of the two genders. The female body has more fluid mass and less skeletal mass which results in decreased strength of the body. Current review suggests that majority of PTs experience WSMDs within the first five years of their practice. This finding is consistent with previous studies. Young PTs are inexperienced and lack the knowledge of alternate techniques which may be the cause for this association. However, authors also pointed out the risk of WMSDs with cumulative exposure due to increased work experience. This result can be confounded by healthy worker effect which means that vulnerable PTs choose to leave the profession early to avoid WMSDs leaving healthy PTs to stay in profession. Increased working hours is also a risk factor for WMSDs, reported by Cromie et al. The consequences most commonly associated with WMSDs were modifying treatment techniques and reducing work hours. Modifying treatment techniques was one strategy used by PTs but the studies did not explain the modifications adopted by PTs. Viera et al also reported modifying treatment techniques as the most common associated consequence of WMSDs. PTs also choose work settings that posed less risk factors or move to administrative positions. WMSDs also affected the daily life of PTs which may cause psychosocial problems. Pediatric and neurological specialties were found more prone to WMSDs. Repeated lifting and transfer activities may explain the association. PTs can prevent WMSDs by adopting the principles of ergonomics in their practice and using proper body mechanics. However the risk of developing WMSDs is still high even when proper body mechanics are used. Prevention of WMSDs is difficult as it is affected by many factors. The incidence of WMSDs can be reduced by steps taken on organizational levels which include introducing more extensive ergonomics into degree programs, decreasing the workload of PTs by increasing support staff, using protective equipment and other. On individual level, learning alternate techniques and reducing continued clinical practice can lead to better outcomes. This review should be considered within its limitations which include limited data search as only one database was used for data retrieval.

\section{CONCLUSION}

Prevalence of work-related musculoskeletal disorders are high among physical therapists. The nature of physical therapy job presents significant risk factors which can lead to work related musculoskeletal disorders. 


\section{REFERENCES}

1. Alexopoulos EC, Stathi I-C, Charizani F. Prevalence of musculoskeletal disorders in dentists. BMC musculoskeletal disorders. 2004;5(1):16.

2. Bork BE, Cook TM, Rosecrance JC, Engelhardt KA,Thomason M-EJ, Wauford IJ, et al. Work-related musculoskeletal disorders among physical therapists. Physical therapy. 1996;76(8):827-35.

3. Molumphy $M$, Unger $B$, Jensen $G M$, Lopopolo RB. Incidence of Work-Related Low Back Pain in Physical Therapists. Physical Therapy. 1985;65(4):482-6.Russo A, Murphy C, Lessoway V, Berkowitz J. The prevalence of musculoskeletal symptoms among British Columbia sonographers. Applied Ergonomics. 2002;33(5):385-93.

4. Gauthy R. Miši no-kostne bolezni. Slabo razumljena» pandemija «Bilbao: Evropska agencija za varnost in zdravje pri delu Pridobljenos https://www etui org/content/download/2247/24739/file/MSD SL pdf (304 2015). 2007.

5. Meh J, Bizovi ar N, Kos N, Jakovljevi M. Work-related musculoskeletal disorders among Slovenian physiotherapists. Journal of Health Sciences. 2020.

6. Jang Y, Chi C-F, Tsauo J-Y, Wang J-D. Prevalence and risk factors of work-related musculoskeletal disorders in massage practitioners. Journal of Occupational Rehabilitation. 2006;16(3):416-29.

7. Vieira ER, Kumar S, Coury HJ, Narayan Y. Low back problems and possible improvements in nursing jobs. Journal of advanced nursing. 2006;55(1):79-89.

8. Anderson SP, Oakman J. Allied health professionals and work-related musculoskeletal disorders: a systematic review. Safety and health at work. 2016;7(4):259-67.

9. Girbig M, Deckert S, Kopkow C, Latza U, Dulon M, Nienhaus A, et al. Work-related complaints and diseases of physical therapists-protocol for the establishment of a "Physical Therapist Cohort"(PTC) in Germany. Journal of Occupational Medicine and Toxicology. 2013;8(1):34.

10. Muaidi QI, Shanb AA. Prevalence causes and impact of work related musculoskeletal disorders among physical therapists. Journal of back and musculoskeletal rehabilitation. 2016;29(4):763-9.

11. Breslin FC, Dollack J, Mahood Q, Maas ET, Laberge M, Smith PM. Are new workers at elevated risk for work injury? A systematic review. Occupational and environmental medicine. 2019;76(9):694-701.

12. Sultan-Taieb H, Parent-Lamarche A, Gaillard A, Stock S, Nicolakakis N, Hong QN, et al. Economic evaluations of ergonomic interventions preventing work-related musculoskeletal disorders: a systematic review of organizational-level interventions. BMC public health. 2017;17(1):935.

13. Abaraogu UO, Ezema Cl, Nwosu CK. Job stress dimension and work-related musculoskeletal disorders among southeast Nigerian physiotherapists. International Journal of Occupational Safety and Ergonomics. 2017;23(3):404-9.

14. Alghadir A, Zafar H, Iqbal ZA, Al-Eisa E. Work-related low back pain among physical therapists in Riyadh, Saudi Arabia. Workplace health \& safety. 2017;65(8):33745.

15. Alnaser MZ, Aljadi SH. Physical therapists with work-related musculoskeletal disorders in the State of Kuwait: A comparison across countries and health care professions. Work. 2019;63(2):261-8.

16. Anyfantis I, Biska A. Musculoskeletal disorders among greek physiotherapists: traditional and emerging risk factors. Safety and health at work. 2018;9(3):314-8.

17. Bae $Y-H$. Relationships between presenteeism and work-related musculoskeletal disorders among physical therapists in the Republic of Korea. International Journal of Occupational Safety and Ergonomics. 2018;24(3):487-92.

18. Bae Y-H, Min KS. Associations between work-related musculoskeletal disorders, quality of life, and workplace stress in physical therapists. Industrial health. 2016;54(4):347-53.

19. Cornwell L, Doyle H, Stohner M, Hazle C. Work-related musculoskeletal disorders in physical therapists attributable to manua therapy. Journal of Manual \& Manipulative Therapy. 2020:1-7.

20. Greiner BA, Nolan S, Hogan DA. WorkRelated Upper Limb Symptoms in HandIntensive Health Care Occupations: A Cross-Sectional Study With a Health and Safety Perspective. Physical Therapy. 2019;99(1):62-73.

21. Islam M, Habib $M$, Hafez $M$, Nahar $N$, Lindstrom-Hazel D, Rahman M Musculoskeletal complaints among physiotherapy and occupational therapy rehabilitation professionals in Bangladesh. Work. 2015;50(3):379-86.

22. Mahajan $R$, Singh $M$. Thumb Pain in Physiotherapists Practicing Manua Therapy: Prevalence and Consequences. Available at SSRN 3587721.2019.

23. Mubeen M, Ans M, Ayaz S, Mohiuddin E, Tufail A, Mubeen F, et al. The Frequency of Thumb Pain Among Physiotherapists Practicing Spinal Manual Therapy in Lahore, Pakistan. Pak J Med Biol Sci. 2018;2(1).

24. Rahimi F, Kazemi K, Zahednejad S, LópezLópez D, Calvo-Lobo C. Prevalence of WorkRelated Musculoskeletal Disorders in Iranian Physical Therapists: A Crosssectional Study. Journal of manipulative and physiological therapeutics. 2018;41(6):503-7.

25. Raoof NAA, Desoky ESME, Farag Y. Work Related Musculoskeletal Disorder among Egyptian Physiotherapists. Bulletin of Faculty of PhysicalTherapy. 2014;19(1).

26. Rasha A, Amir M, Elsayed SE, Dawood RS Work related musculoskeletal disorders among egyptain physical therapists and years of experience. SVU-International Journal of Physical Therapy and Science. 2019;1(1):1-7.

27. Rossettini G, Rondoni A, Schiavetti I, Tezza S, Testa M. Prevalence and risk factors of thumb pain in Italian manual therapists: An observational cross-sectional study. Work. 2016;54(1):159-69.

28. Vieira ER, Svoboda S, Belniak A, Brunt D, Rose-St Prix C, Roberts L, et al. Workrelated musculoskeletal disorders among physical therapists: an online survey. Disability and rehabilitation. 2016;38(6):552-7.

29. Ezzatvar Y, Calatayud J, Andersen LL, Aiguadé R, Benítez J, Casaña J. Professional experience, work setting, work posture and workload influence the risk for musculoskeletal pain among physical therapists: a cross-sectional study International Archives of Occupational and Environmental Health. 2020;93(2):189-96.

30. Truszczy ska A, Scherer A, Drzał-Grabiec J. The occurrence of overload at work and musculoskeletal pain in young physiotherapists. Work. 2016;54(3):609-16.

31. Gharote G, Piwal P, Yeole U, Adakkite R, Gawali P. Prevalence of common work related musculoskeletal pain in physiotherapy practitioners. European journal of pharmaceutical and medica research. 2016;3:398-402.
32. Alperovitch-Najenson D, Treger I, Kalichman L. Physical therapists versus nurses in a rehabilitation hospital: comparing prevalence of work- related musculoskeletal complaints and working conditions. Archives of environmental \& occupational health. 2014;69(1):33-9.

33. Ngan K, Drebit S, Siow S, Yu S, Keen D, Alamgir H. Risks and causes of musculoskeletal injuries among health care workers. Occupational medicine. 2010;60(5):389-94.

34. Rugelj D. Low back pain and other workrelated musculoskeletal problems among physiotherapists. Applied ergonomics. 2003;34(6):635-9.

35. Wajon A, Ada L. Prevalence of thumb pain in physical therapists practicing spinal manipulative therapy. Journal of Hand Therapy. 2003;16(3):237-44.

36. Cromie JE, Robertson VJ, Best MO. Workrelated musculoskeletal disorders and the culture of physical therapy. Physical therapy. 2002;82(5):459-72.

37. Regla P, James G. Thumb pain in physiotherapists: a preliminary study. British journal of therapy and rehabilitation. 1999;6(10):505-9.

38. Alrowayeh HN, Alshatti TA, Aljadi SH, Fares M, Alshamire MM, Alwazan SS. Prevalence, characteristics, and impacts of workrelated musculoskeletal disorders: a survey among physical therapists in the State of Kuwait. BMC musculoskeletal disorders. 2010;11(1):116.

39. Adegoke BO, Akodu AK, Oyeyemi AL. Workrelated musculoskeletal disorders among Nigerian physiotherapists. BMC musculoskeletal disorders. 2008;9(1):112.

40. Nordin NAM, Leonard JH, Thye NC. Workrelated injuries among physiotherapists in public hospitals: a Southeast Asian picture. Clinics. 2011;66(3):373-8.

41. Glover W, McGregor A, Sullivan C, Hague J. Work-related musculoskeletal disorders affecting members of the Chartered Society of Physiotherapy. Physiotherapy. 2005;91(3):138-47.

42. McMahon M, Stiller K, Trott P.The prevalence of thumb problems in Australian physiotherapists is high: an observational study. Australian Journal of physiotherapy. 2006;52(4):287-92.

43. Iqbal Z, Alghadir A. Prevalence of workrelated musculoskeletal disorders among physical therapists. Med Pr. 2015;66(4):45969.

44. West DJ, Gardner D. Occupational injuries of physiotherapists in North and Central Queensland. Australian Journal of Physiotherapy. 2001;47(3):179-86.

45. Salik Y, Ozcan A. Work-related musculoskeletal disorders: a survey of physical therapists in Izmir-Turkey. BMC musculoskeletal disorders. 2004:5(1):27.

46. Nkhata LA, Zyaambo C, Nzala S, Siziya S. Work-related musculoskeletal disorders: Prevalence, contributing factors and coping strategies among physiotherapy personnel in Lusaka, Kitwe and Ndola districts, Zambia. Medical journal of Zambia. 2010;37(4):262-7.

47. Vieira ER, Schneider P, Guidera C, Gadotti IC, Brunt D. Work-related musculoskeletal disorders among physical therapists: A systematic review. Journal of Back and Musculoskeletal Rehabilitation. 2016;29:417-28.

48. Marras W, Davis K, Kirking B, Bertsche P. A comprehensive analysis of low-back disorder risk and spinal loading during the transferring and repositioning of patients using different techniques. Ergonomics. 1999;42(7):904-26. 